\title{
Cancer Illness
}

among Residents of Miyagi Prefecture, Japan, 1951

By

Mitsuo Segi, Ichiro Fukushima, Yoshihiko Mikami, (做木三雄) (福島一郎) (三神芳蒝)

\section{Susumu Fujisaku and Minoru Kurihara}

（藤 知遏） (栗 原登)

From the Department of Public Health, Faculty of Medicine, Tohoku University, Sendai. Director: Prof. M. Segi

(Received for publication, July 14, 1953)

In Japan deaths by tuberculosis have markedly decreased these several years, while the proportion of deaths by cerebral haemorrhage and cancer ("cancer" mentioned here in this report means malignant neoplasm) has become large in the total deaths. In 1953, when the deaths of the Japanese people due to various causes were recorded by their order, cerebral haemorrhage occupied the first place, followed by cancer and tuberculosis. To make an effective cancer control, it is not sufficient to study only death cases, but, it is essential to know the status of geographical morbidity of cancer. In various foreign countries, geographical surveys on cancer patients have been conducted and the results have been published. In Japan, however, such kind of survey has not yet been conducted.

To provide such information, the Department of Public Health, Tohoku University collected the reports on cancer patients treated by physicians in whole districts of Miyagi Prefecture and tabulated the results with the cooperation of Miyagi Prefectural Government and Miyagi Prefectural Medical Association (President: Dr. Yoshihiko Koga). This survey was started with the patients seen or treated during 1951. The results of 1951 are reported here, and the results of 1952 are scheduled to be published later.

Miyagi Prefecture thus surveyed is located in the north east of Honshu (the mainland), Japan and is a coastal area of the Pacific Ocean, with the population of approximately 1.7 million and the area of 7,000 square $\mathrm{km}$. City of Sendai is the political and cultural center of this prefecture. The Tohoku University is located here in Sendai. Adjacent areas to the prefecture have lower cultural level than Miyagi Prefecture. So many cancer patients of adjacent prefectures receive treatment at clinics 
of this university. But few residents of Miyagi Prefecture visit hospitals of other prefectures.

In Japan, medical institutions which have twenty beds or more and can meet the definite standards prescribed are called "hopsitals" and those which have less than twenty beds are called "medical offices." In 1951, there were 88 hospitals and 731 medical offices, and the Tohoku University Hospital was the largest of all.

\section{Survey Method}

We distributed survey schedules to all hospitals and medical offices in the prefecture and required to record all the cancer patients who were seen, treated or observed for any kind of cancer and all the cancer deaths whose death certificates were made in those hospitals and medical offices during the period from Jan. 1, 1951 to Dec. 31, 1951 inclusive. The schedules were returned to the Department of Public Health of Tohoku University. The schedule made provisions for recording name, address, sex, age, marital status of the patients, previous consultations by other clinics or hospitals, first subjective symptom, date, first subjective symptom appeared, first seen (in the clinic concerned), diagnosis made, and last seen for cancer, clinical diagnosis, diagnostic methods, histological diagnosis, methods of therapy, period of hospitalization, and whether alive or dead. We then made individual cards of the patients in accordance with the schedules returned. If the same patient was reported from more than one place, only one card was made to avoid counting him as two or more cases. Moreover, in order to find out deaths occurred to the patients reported and to obtain the completeness of reporting from hospitals and medical offices, members of the Department visited 15 Health Centers in this prefecture and recorded cancer deaths by the copies of death notifications of 1951 and 1952. The Department of Public Health of Tohoku University assumed the whole responsibility for the computation of the data thus collected.

Number of Cases Reported and Completeness of Reporting

A total of 2,711 cases of cancer were seen in 1951. In this survey, nonresidents accounted for nearly one-sixth of the cases seen. The proportion of cases seen during the study year that the first subjective symptom had appeared in earlier years-approximately two-fifths (Table I).

Of the 1,061 cases of cancer among male residents seen during 1951, 35 per cent had presented their first subjective symptoms during a prior year; of the 1,201 cases among female residents, 45 per cent had presented the first subjective symptom prior to 1951 .

By checking all death certificates on which cancer is recorded in the 
TABLE I

Cases of Cancer First Subjective Symptom Appeared

During and Prior to the Study Year, 1951

\begin{tabular}{|c|c|c|c|c|}
\hline & \multirow[b]{2}{*}{ Total } & \multicolumn{2}{|c|}{$\begin{array}{l}\text { First subjective symptom } \\
\text { appeared during study year }\end{array}$} & \multirow{2}{*}{$\begin{array}{c}\text { First subjective } \\
\text { symptom } \\
\text { appeared } \\
\text { prior to } \\
\text { study year }\end{array}$} \\
\hline & & $\begin{array}{l}\text { reported } \\
\text { cases }\end{array}$ & $\begin{array}{l}\text { recorded from } \\
\text { death certific- } \\
\text { ates }\end{array}$ & \\
\hline $\begin{array}{l}\text { Total } * \\
\text { Residents }\end{array}$ & 2,711 & 972 & 566 & 1,166 \\
\hline $\begin{array}{l}\text { All cases } \\
\text { Male } \\
\text { Female }\end{array}$ & $\begin{array}{l}2,262 \\
1,061 \\
1,201\end{array}$ & $\begin{array}{l}784 \\
386 \\
398\end{array}$ & $\begin{array}{l}566 \\
302 \\
264\end{array}$ & $\begin{array}{l}912 \\
373 \\
539\end{array}$ \\
\hline $\begin{array}{c}\text { Nonresidents } \\
\text { All cases } \\
\text { Male } \\
\text { Female }\end{array}$ & $\begin{array}{l}439 \\
209 \\
230\end{array}$ & $\begin{array}{r}187 \\
99 \\
88\end{array}$ & $=$ & $\begin{array}{l}252 \\
110 \\
142\end{array}$ \\
\hline
\end{tabular}

* Including 10 cases unknown address and date first subjective symptom appeared.

TABLE II

Total Resident Cases First Subjective Symptom Appeared During the Study Year and Cases Recorded from Death Certificates only, by Sex and Primary Site, 1951

\begin{tabular}{|c|c|c|c|c|}
\hline \multirow{3}{*}{ Primary site } & \multirow{3}{*}{$\begin{array}{l}\text { Total } \\
\text { case } / /\end{array}$} & \multicolumn{3}{|c|}{$\begin{array}{l}\text { First subjective symptom } \\
\text { appeared during study year }\end{array}$} \\
\hline & & \multirow[t]{2}{*}{ total } & \multicolumn{2}{|c|}{$\begin{array}{l}\text { recorded from } \\
\text { death certificates } \\
\text { only }\end{array}$} \\
\hline & & & number & percent \\
\hline $\begin{array}{c}\text { All cases } \\
\text { Male } \\
\text { Female }\end{array}$ & $\begin{array}{l}2,262 \\
1,061 \\
1,201\end{array}$ & $\begin{array}{r}1,350 \\
688 \\
662\end{array}$ & $\begin{array}{l}566 \\
302 \\
264\end{array}$ & $\begin{array}{l}41.9 \\
43.9 \\
39.9\end{array}$ \\
\hline $\begin{array}{l}\text { Buccal cavity and pharynx } \\
\text { Digestive organ and peritoneum } \\
\text { Respiratory system } \\
\text { Breast } \\
\text { Female genital organs* } \\
\text { Male genital organs } \\
\text { Urinary organs } \\
\text { Skin } \\
\text { Other and unspecified sites } \dagger \\
\text { Eye, brain and nervous system } \\
\text { Lymphomasł } \\
\text { Leukemias and aleukemias } \\
\text { Sarcomas\$ } \\
\text { Other and unspecified malignant neoplasms }\end{array}$ & $\begin{array}{r}21 \\
1,406 \\
83 \\
119 \\
363 \\
18 \\
19 \\
19 \\
39 \\
12 \\
59 \\
34 \\
53 \\
17\end{array}$ & $\begin{array}{r}12 \\
929 \\
44 \\
51 \\
158 \\
7 \\
10 \\
8 \\
18 \\
7 \\
37 \\
31 \\
30 \\
8\end{array}$ & $\begin{array}{r}4 \\
446 \\
19 \\
6 \\
38 \\
3 \\
6 \\
2 \\
1 \\
13 \\
16 \\
8 \\
5\end{array}$ & $\begin{array}{r}33.4 \\
48.0 \\
43.1 \\
11.8 \\
24.1 \\
42.9 \\
60.0 \\
0 \\
11.1 \\
14.3 \\
35.2 \\
51.6 \\
26.7 \\
62.5\end{array}$ \\
\hline
\end{tabular}

* Including chorionepithelioma. + Carcinoma only. \$ Including Hodgkin's disease. $\$$ Including all sites. // Total cases, first subjective symptom appeared during or prior to the study year. 
column of cause of death against the file of reported cases, it was possible in this survey to find out cancer deaths which were not reported as cases by hospitals or medical offices. In 1951, cancer deaths that had not been reported as cases accounted for 42 per cent (566 cases) of the total known resident cases. Among the total of patients, the percentage by site of the cases, not reported from hospitals or medical offices but confirmed only by death certificates are indicated in Table II.

It is the fact that in Japan, there are many cancer patients expected to die are discharged from hospitals and die at their own houses. In Miyagi Prefecture in 1949, 1950 and 1951, among the total of cancer deaths, the percentage of deaths at hospitals and medical offices was 18.8 per cent in male and 15.3 in female and the rest almost all died at their own houses. There are many physicians who are requested by the families of dead persons to visit their houses only to make death certificate and, in such case, most of these physicians are not the physicians who cared of the cancer patients.

It is presumed that many physicians who were in such condition did not report of death in this survey. For this reason, it is presumed that there will be found out a large percentage of deaths not reported in this survey.

The number of hospitals who reported survey schedules and the hospitals to which members of the Department of Public Health visited to make survey schedules was 63. That of medical offices was 176 . The number of beds of hospitals from which we obtained the survey schedules corresponds to 86 per cent of the total of beds in all hospitals.

\section{Accuracy of Reports}

Each respondent was requested to indicate on the report whether the diagnosis of cancer was confirmed by a microscopic examination of tissue, operation or X-ray examination. Table III shows this information for this survey, classified by primary site of neoplasm.

Whether the diagnosis of cancer is confirmed by microscopic examination depends in part upon the accessibility of the tissue affected, especially for living cases. For example, among patients with cancer of the liver and biliary passages, an inaccessible site, 2.6 per cent of diagnosis were confirmed microscopically, while 43.2 per cent of cancer of the uterus, an accessible site, were microscopically confirmed. It seems that percentage of diagnosis by operation or X-ray examination can become reference data for accuracy of diagnosis.

\section{Incidence, Prevalence and Mortality Rates}

Incidence, prevalence and motality rates were computed based on 
TABLE III

Percentages of Reported Cases of Cancer with Microscopic Confirmation, Operation and X-ray, by Primary Site, 1951

\begin{tabular}{|c|c|c|c|c|c|c|c|}
\hline \multirow[t]{2}{*}{ Primary site } & \multirow{2}{*}{ 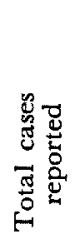 } & \multicolumn{2}{|c|}{$\begin{array}{l}\text { Microscopic } \\
\text { confirma- } \\
\text { tion }\end{array}$} & \multicolumn{2}{|c|}{$\begin{array}{c}\text { Operated } \\
\text { cases, without } \\
\text { mentioning } \\
\text { microscopic } \\
\text { confirmation }\end{array}$} & \multicolumn{2}{|c|}{$\begin{array}{c}\text { X-ray } \\
\text { examina- } \\
\text { tion } \\
\text { only }\end{array}$} \\
\hline & & $\underset{\text { ber }}{\text { num- }}$ & $\%$ & $\begin{array}{c}\text { num- } \\
\text { ber }\end{array}$ & $\%$ & $\begin{array}{c}\text { num- } \\
\text { ber }\end{array}$ & $\%$ \\
\hline Total & 1,515 & 425 & 28.1 & 352 & 23.2 & 323 & 21.3 \\
\hline Buccal cavity and pharynx & 17 & 9 & 52.9 & 1 & 5.9 & - & \\
\hline Digestive system & 851 & 134 & 15.7 & 195 & 22.9 & 294 & 34.5 \\
\hline Esophagus & 69 & 11 & 15.9 & 3 & 4.3 & 39 & 56.5 \\
\hline Stomach & 598 & 99 & 16.6 & 157 & 26.3 & 213 & 35.6 \\
\hline Intestines & 24 & 9 & 37.4 & 4 & 16.7 & 1 & 4.2 \\
\hline Rectum & 61 & 13 & 21.4 & 20 & 32.8 & 4 & 6.5 \\
\hline Liver and biliary passages & 78 & 2 & 2.6 & 6 & 7.2 & 27 & 34.8 \\
\hline Pancreas & 17 & $=$ & 0 & 3 & 17.7 & 10 & 58.9 \\
\hline Peritoneum & 4 & - & 0 & 2 & 50.0 & - & 0 \\
\hline Respiratory system & 32 & 12 & 37.6 & 1 & 3.1 & 12 & 37.6 \\
\hline Accessory sinuses & 23 & 6 & 26.0 & 3 & 13.0 & 4 & 17.4 \\
\hline Breast & 105 & 33 & 31.4 & 54 & 51.4 & $\ldots$ & 0 \\
\hline Uterus $\dagger$ & 257 & 111 & 43.2 & 66 & 25.7 & - & 0 \\
\hline Other female genital organst & 35 & 11 & 31.4 & 10 & 28.6 & 3 & 8.6 \\
\hline Male genital organs & 14 & 8 & 57.0 & 1 & 7.1 & - & 0 \\
\hline Urinary organs & 11 & 3 & 27.4 & 2 & 18.2 & 3 & 27.4 \\
\hline Skin & 16 & 7 & 43.6 & 3 & 18.7 & - & 0 \\
\hline Thyroid gland & 15 & 11 & 73.4 & 2 & 13.3 & - & \\
\hline Other and unspecified sites§ & 19 & 7 & 36.8 & 2 & 10.5 & 3 & 15.8 \\
\hline Eye & 7 & 6 & 86.0 & - & 0 & - & 0 \\
\hline Brain and nervous system & 5 & 4 & 80.0 & - & 0 & - & 0 \\
\hline Lymphomas & 37 & 22 & 59.4 & 1 & 2.7 & - & \\
\hline Hodgkin's disease & 6 & 4 & 66.7 & 2 & 33.4 & - & 0 \\
\hline Leukemias and aleukemias & 17 & 14 & 82.4 & - & 0 & - & 0 \\
\hline Sarcomas// & 40 & 20 & 50.0 & 8 & 20.0 & 2 & 5.0 \\
\hline Other and unspecified malignant neoplasms & 8 & 3 & 37.6 & 1 & 12.5 & 1 & 12.5 \\
\hline
\end{tabular}

* Excluding accessory sinuses + Excluding chorionepithelioma. I Including chorionepithelioma. §Carcinoma only. // Including all sites.

the figure obtained by this survey. The full value of morbidity data can be obtained only by relating the number of cases to the population from which they are drawn through the computation of rates per unit of population. The population used in computing the rates given in this report was based on the October 1, 1950 population census (though this is the previous year's population of this survey, this is the newest one officially announced). The total population of Miyagi Prefecture is enumerated at 1,663, 442 in 1950 (829,050 males and 834, 392 females). The rates were defined as follows:

1. Incidence rate. The number of cases whose first subjective symptom of cancer appeared during the study year, per 100,000 popullation. In this kind of survey in the United States, incidence rate is 
computed by the number of cases first diagnosed with cancer during the study year instead of by the above mentioned definition. But in this survey, we considered it is difficult to make this date of diagnosis standard. The reasons are that it is hard to require full reports from all physicians and, in Japan, most physicians who made the first diagnosis do not tell patients as cancer cases apparently. In the survey schedule, there is an item "Date first seen with cancer" in the United States, but since there will be probability not to obtain complete answers from patients, we made an item "Date first subjective symptom appeared" in addition. The defects of our method are that in case subjective symptom first appeared at the end of the study year and first seen by a physician next year, this case will not be recorded. Accordingly the first year's study will be underestimated than the exact number. Now at present, we are studying at 1952 study year. If we finish enumeration of this 1952 year's survey, we shall be able to obtain the cases that symptom first appeared at the end of 1951 and seen by physicians in 1952 .

2. Prevalence rate. The number of cases known to have had cancer at any time during the study year, per 100,000 population. (The patients who visited physicians for diagnosis only during the study year and did not receive any medical care were included.)

3. Mortality rate. The number of deaths during the study year, per 100,000 population. We considered such case that, in the death certificate, in the column of "Disease or condition directly leading to death" as a matter of course, in that of "Antecedent causes" or "Other significant conditions" also cancer is recorded as cancer death. In Japan, the copies of important columns of death certificates have been kept in Health Centers since 1948.

The number of resident cases of cancer in 1951 in the prefecture collected from this survey and death certificates is $2,262,47$ per cent in male and 53 percent in female. The items of 2,262 resident cases are as follow: 1,350 persons ( 60 percent of total cases) were cases whose first subjective symptom appeared in 1951, including 566 deaths revealed by death certificates only (we counted backward from the interval between onset and death recorded on death certificates to determine when the symptom first appeared in the death cases not reported from physicians); 912 cases (40 per cent of total) presented their first symptom during 1950 or in previous year and received medical care or visited physicians for only being observed their process during 1951.

Thus, 81 out of every 100,000 persons living in Miyagi Prefecture had first subjective symptom of cancer during the study year, and 136 out of every 100,000 persons were under treatment or under observation for cancer during this period (Table IV). 
TAB LE IV

Cancer Incidence, Prevalence and Mortality Rates per 100,000

Population, by Sex and Primary Site, 1951

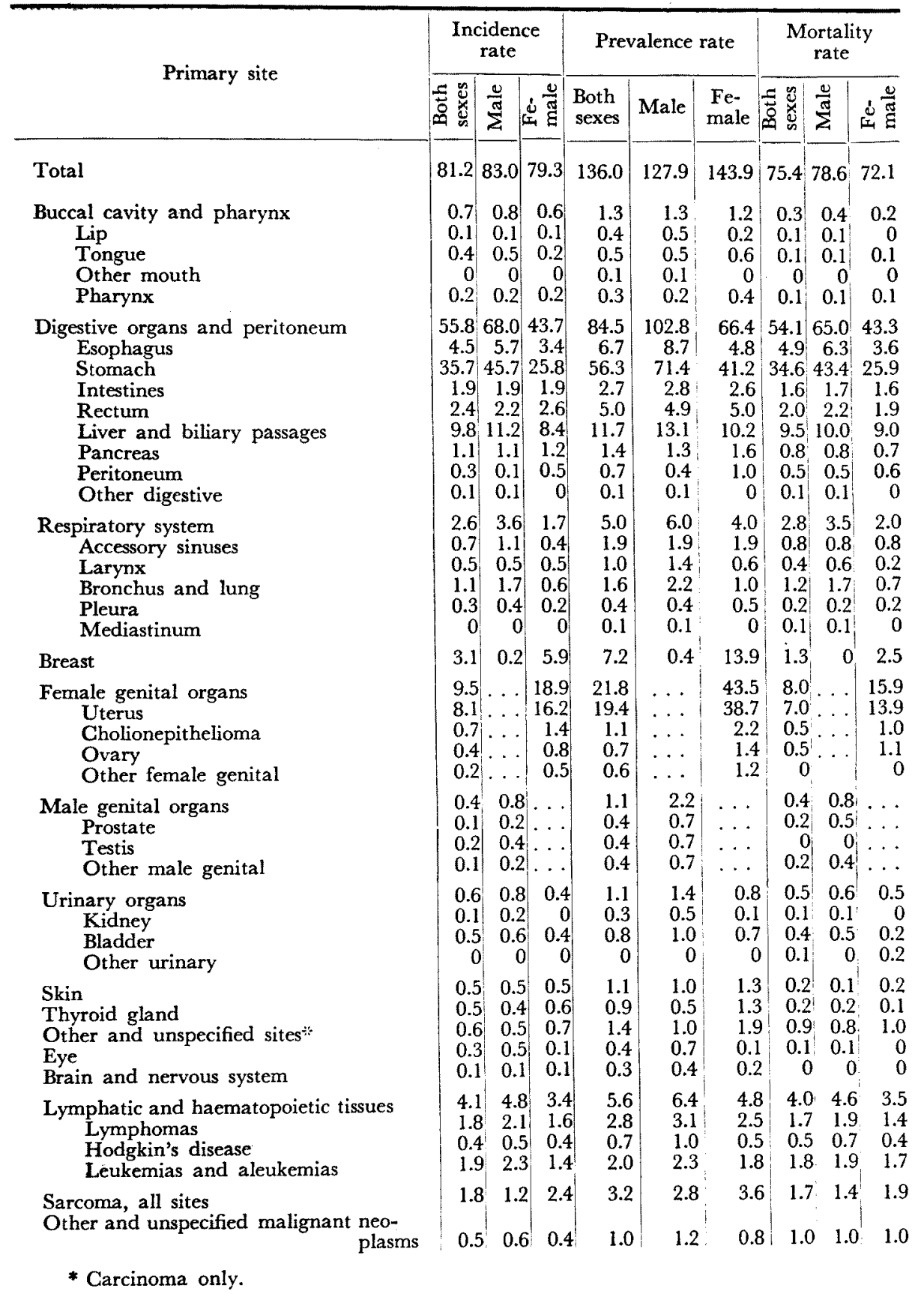


There were 1,254 resident deaths in 1951 for cancer, a mortality rate of 75 per 100,000 population.

The recorded cancer incidence rate among males exceeded that for females by about 5 per cent ( 83.0 compared to 79.3$)$. But in prevalence rate, the relation is opposite. The female cancer prevalence rate exceeded the male rate by about 12 per cent (143.9 compared to 127.9).

This apparent difference is a reflection of the large number of cases of uterus and breast cancer among female.

Male incidence rates were greater than those of the females for cancer of the esophagus, stomach, and bronchus and lung. The incidence rate of bronchus and lung cancer for males was three times as great as that for females.

In cancer mortality, the male rate was 9 per cent greater than the female rate (79 and 72 per 100,000$)$.

\section{Survival Rates}

Data on resident cases of cancer newly diagnosed in 1951 were analyzed with respect to survival after diagnoses. The basic information on survival was obtained by checking the names of reported cases against death certificates for the period January 1, 1951-December 31, 1952.

Fifty-two out of every 100 cases newly diagnosed in 1951 survived 12 or more months after diagnosis while 63 out of every 100 survived at

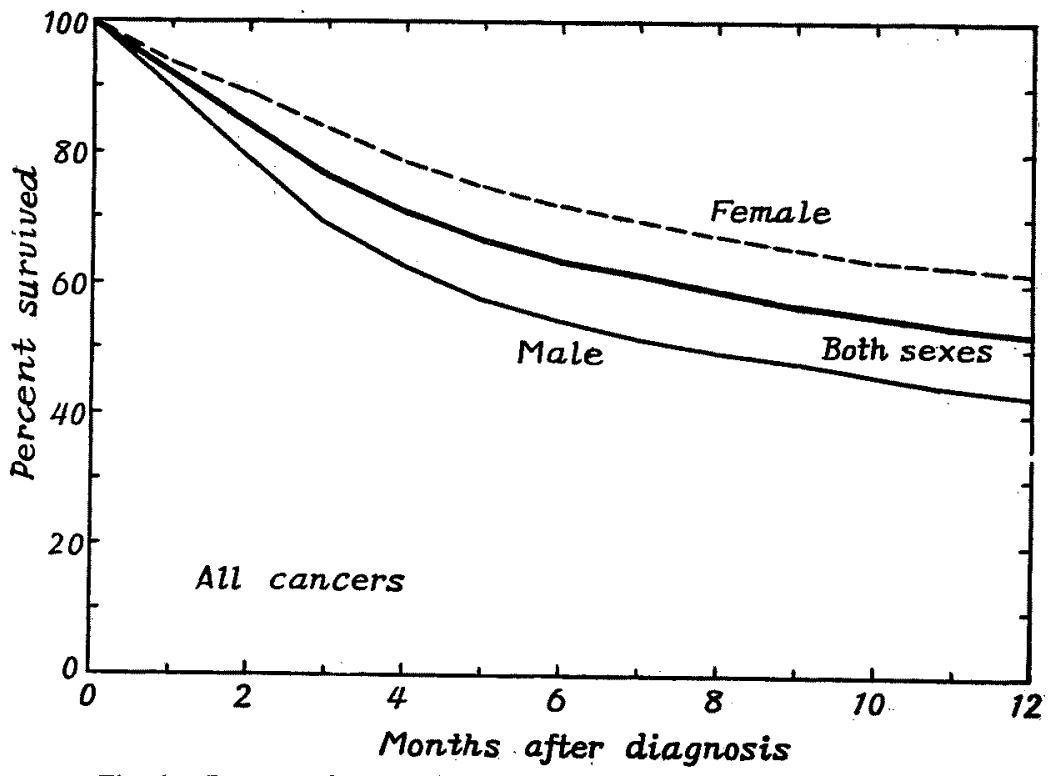

Fig. 1. Percent of cases of cancer diagnosed in 1951 surviving to end of month indicated; all sites, by sex 
TABLE V

Six- and Twelve-month Survival Rates for Cases of Cancer

Newly Diagnosed during 1951, by Sex, Age and Primary Site

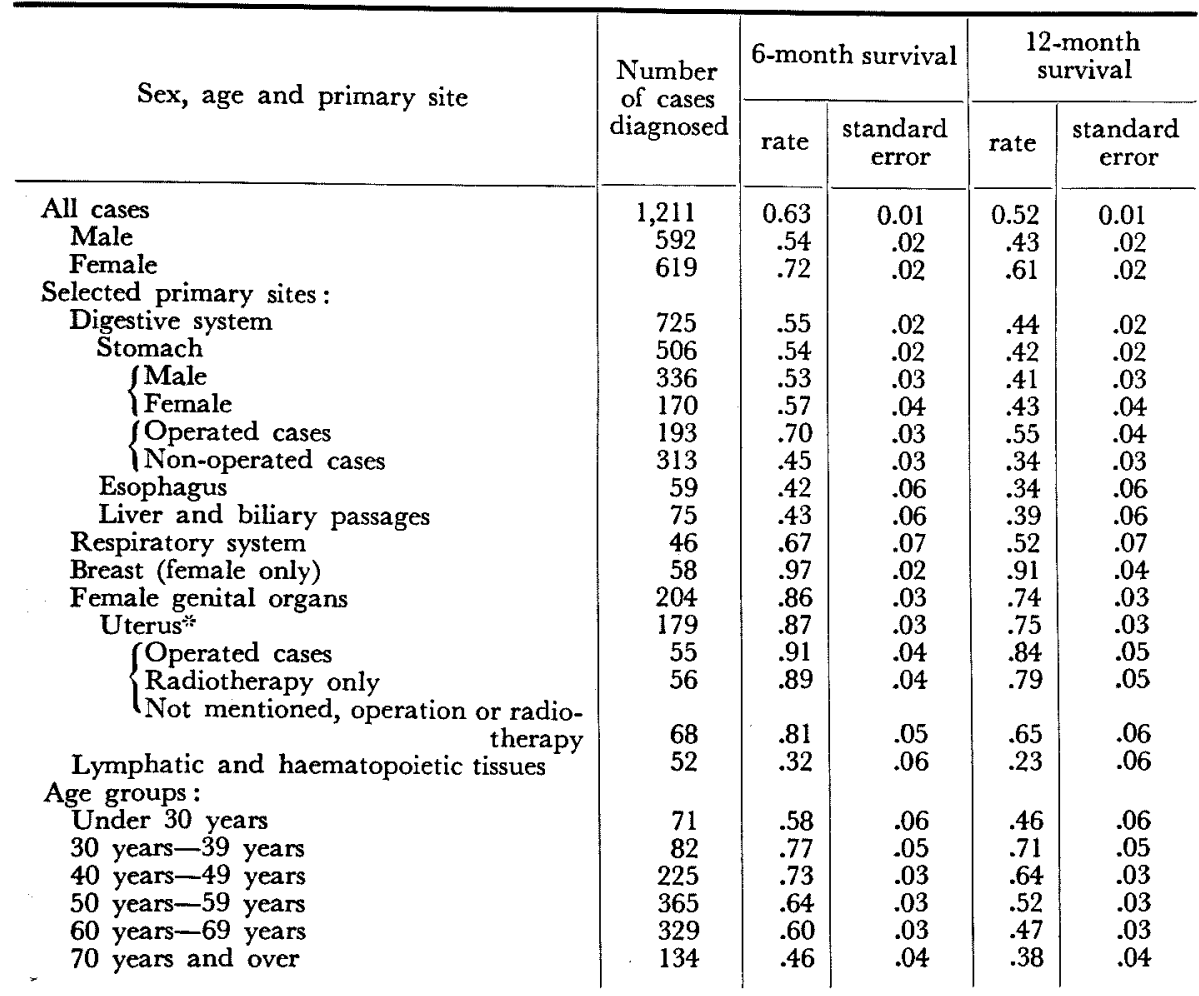

* Excluding cholionepithelioma.

least 6 months. In other words, 5 out of every 10 patients died within 1 year of diagnosis, but 4 of these died during the first 6 months. This relationship reflects the relatively high death rate among cancer patients during the first few months after diagnosis. The survival rates given in Table $\mathrm{V}$ and in Figs. 1 and 2.

The variation in survival rates naturally depends on stage at diagnosis. In this survey, we requested recording on stage at diagnosis. But we got little recording of accuracy.

Survival rates varied appreciably by sex. The male 12-month survival rate was 43 compared to 61 for female. The differences in survival rates among both sexes are mainly influenced by the cases of the cancer of the uterus and the breast.

Among the various sites, the lowest rates were found among lymphomas (including Hodgkin's disease), leukemias and aleukemias (23 percent 

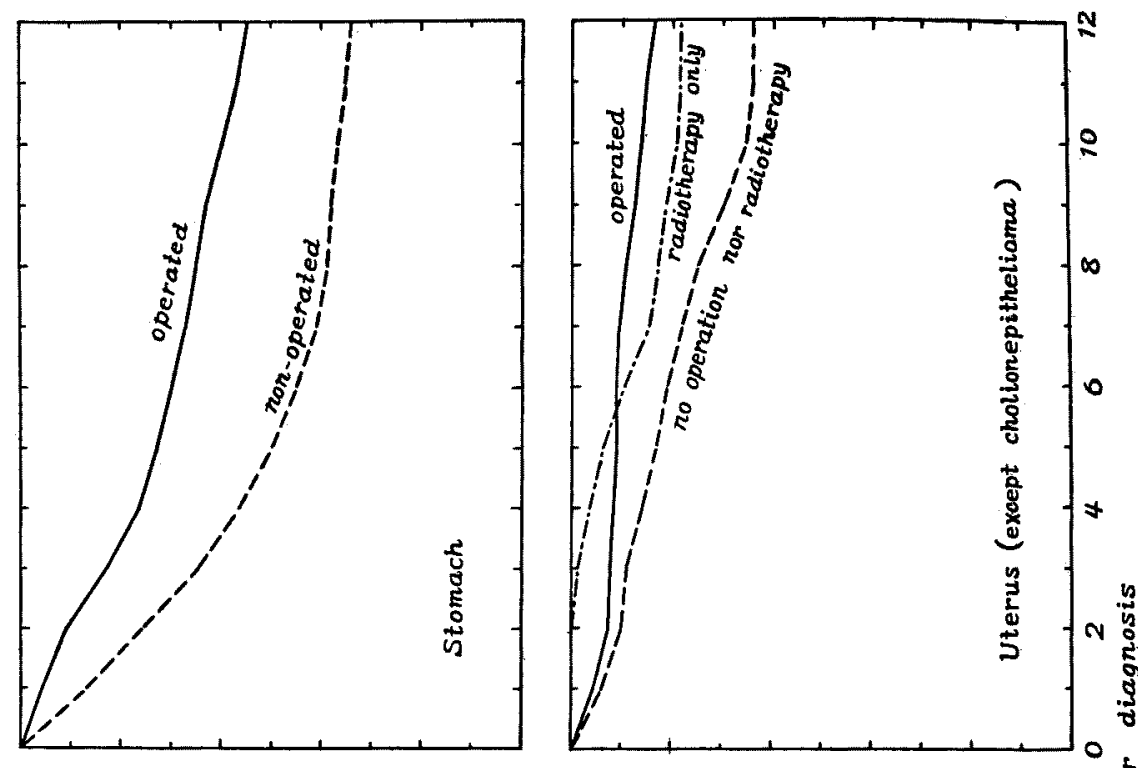

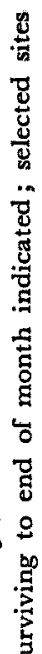
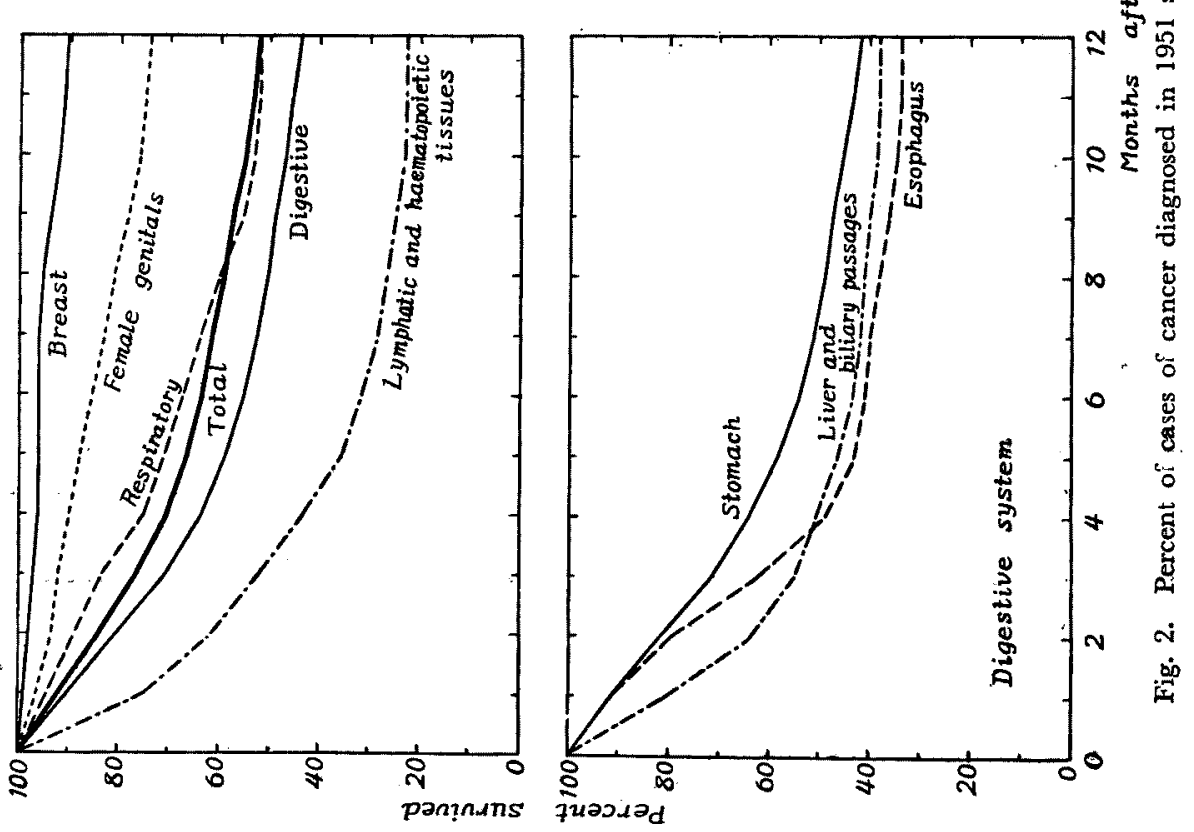

survived 1 year, and 32 per cent survived 6 months), esophagus (34 per cent and 42 per cent), and liver and biliary passages (39 per cent and 43 per cent). These may be compared with rates of 91 per cent survived 1 year and 97 per cent survived 6 months for the breast. 
We computed survival rate on cancer of the stomach and uterus according to that whether operation was made or not. Viewing the results, in stomach cancer, if operated, 12-month survival rate is 55 per cent and if not operated, 34 per cent. In uterus cancer, if operated, 12month survival rate is 84 per cent. In case only radiotherapy was given, 79 per cent. In case of no operation nor radiotherapy recorded, 12month survival rate is 65 per cent.

\section{SUMMARY}

1. We distributed survey schedules to all the hospitals and medical offices in Miyagi Prefecture, Japan which has about 1,663,000 population and collected reports on all the cancer patients seen or treated during 1951. At the same time, we studied at the cases that cancer is recorded as cause of death out of the copies of the death notifications kept in all the Health Centers in the prefecture. The results obtained by the above mentioned two kinds of survey were enumerated.

2. The case number reported from hospitals and medical offices was 2,804 in total. However, since one patient is likely reported from two or more of hospitals and/or medical offices, the exact number was 1,964. Among the patients, the number of residents of Miyagi Prefecture is 1,515. As there are no any other hospitals equal to or larger than the Tohoku University Hospital in scale in adjacent prefectures, many persons visit this hospital from adjacent prefectures. It is presumed that few residents of Miyagi Prefecture ask to have examination and treatment to hospitals in other prefectures.

The number of such cases that "cancer" was recorded in any column of cause of death in the death certificates was 1,254 (male 652, female 602). Among these cases, 507 were reported from hospitals and medical offices. In 1951, out of residents of Miyagi Prefecture, the exact number of known cancer cases was 2,262 (male 1,061, female 1,201). Among them, 1,350 presented first subjective symptom in the study year.

3. An incidence rate of cancer patients who felt their first subjective symptom in 1951 was 81 (male 83, female 79) per 100,000 population. A prevalence rate of all the cancer cases, cancer deaths and cancer cured cases that physicians dealt with for some reasons in the study year was 136 (male 128 , female 144 ) per 100,000 population. A mortality rate of the cases that cancer were recorded in any column of cause of death in the death certificates was 75 (male 79, female 72) per 100,000 population.

4. Viewing incidence cases by site, in male stomach $(55 \%$ of total male incidence cases), liver and biliary passages (14\%), and esophagus $(7 \%)$ show large number in frequency. Leukemias and aleukemias, rectum, lymphomas, intestine, and lung succeed the former, but they 
have a small proportion. In female, stomach (32\% of total female incidence cases), uterus (21\%), liver and biliary passages (11\%), and breast $(7 \%)$, esophagus, rectum, and sarcomas succeed the former. Skin and prostate cancer occurs markedly in small frequency.

5. The 12-month survival rate of newly diagnosed patients in 1951 is male, 43 per cent and female, 61 per cent. In stomach cancer male, 41 per cent and female, 43 per cent after twelve months and male, 53 per cent and female, 57 per cent after six months. Comparing a survival rate of a group of patients whose stomach and uterus cancer was operated to that of non-operated group of patients, it was recognized that a survival rate of the former is higher than that of the latter.

This work was carried out by a Grant from the Foundation for Scientific Research of the Ministry of Education.

M. Segi

\section{References}

1) National Cancer Institute of the National Institutes of Health, Public Health Service, Federal Security Agency, U.S.A., Cancer Morbidity Series, 1950-1952 (Public Health Service Publication Nos. 13, 65, 67, 112, 126, 152, 178, 216, 217, 244). 